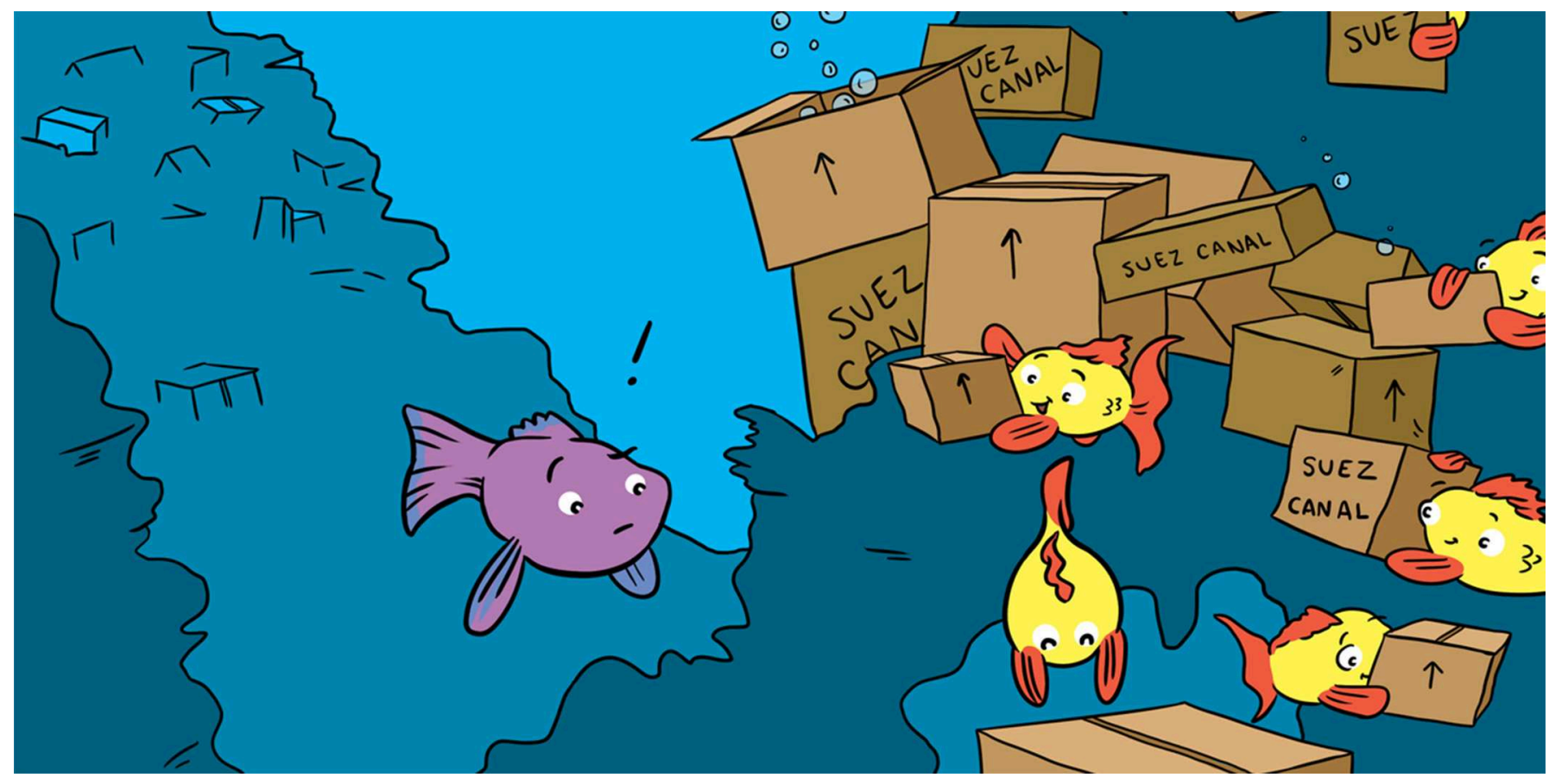

\title{
HUMAN ACTIVITIES HELP ALIEN SPECIES TO INVADE THE MEDITERRANEAN SEA
}

\section{loannis Giovos ${ }^{1 *}$, Stelios Katsanevakis ${ }^{2}$, Marta Coll ${ }^{3,4}$, Chiara Piroddi ${ }^{5}$, Jeroen Steenbeek ${ }^{4}$, Frida Ben Rais Lasram ${ }^{6}$, Argyro Zenetos ${ }^{7}$ and Ana Cristina Cardoso ${ }^{1}$}

${ }^{1}$ European Commission, Joint Research Centre, Ispra, Italy

${ }^{2}$ Department of Marine Sciences, University of the Aegean, Mytilene, Greece

${ }^{3}$ Marine Renewal Resources Department, Institute of Marine Science (ICM-CSIC), Barcelona, Spain

${ }^{4}$ Ecopath International Initiative Research Association, Barcelona, Spain

${ }^{5}$ European Commission, Joint Research Centre, Directorate D-Sustainable Resources, Ispra, Italy

${ }^{6}$ Laboratoire d'Océanologie et de Géosciences, Univ. Littoral Côte d'Opale, Univ. Lille, CNRS, UMR8187, LOG, Wimereux, France ${ }^{7}$ Hellenic Centre for Marine Research, Institute of Marine Biological Resources and Inland Waters, Anavyssos, Greece

YOUNG REVIEWERS: KOREA FOREIGN SCHOOL AGES: $12-13$
The Mediterranean Sea is one of the largest seas in the world and has a great diversity of marine species. Currently, the Mediterranean Sea is facing various threats, with alien species being one of the most important. To address this problem, it is very important to understand how alien species arrive and where they are in the Mediterranean Sea. Furthermore, it is necessary to evaluate whether alien species affect native marine species, and if so, what kind of effects they have. This article will describe our current knowledge about the effects of alien species in the Mediterranean Sea. 
Figure 1

Ways that citizens can contribute to the sightings of alien species. (A) Students and teachers can take samples and study them in the school lab. (B) SCUBA divers or (C) snorkelers can make visual observations and take pictures with underwater cameras.

(D) Fishermen can study their catches to see whether the species in an area are changing. By reporting their findings on citizen science platforms, all citizens can contribute to the early detection of alien species.

\section{ALIEN SPECIES}

Species found out of their native home range, moved to new areas due to human activities.

\section{NATIVE SPECIES}

Species that occur naturally in an area.

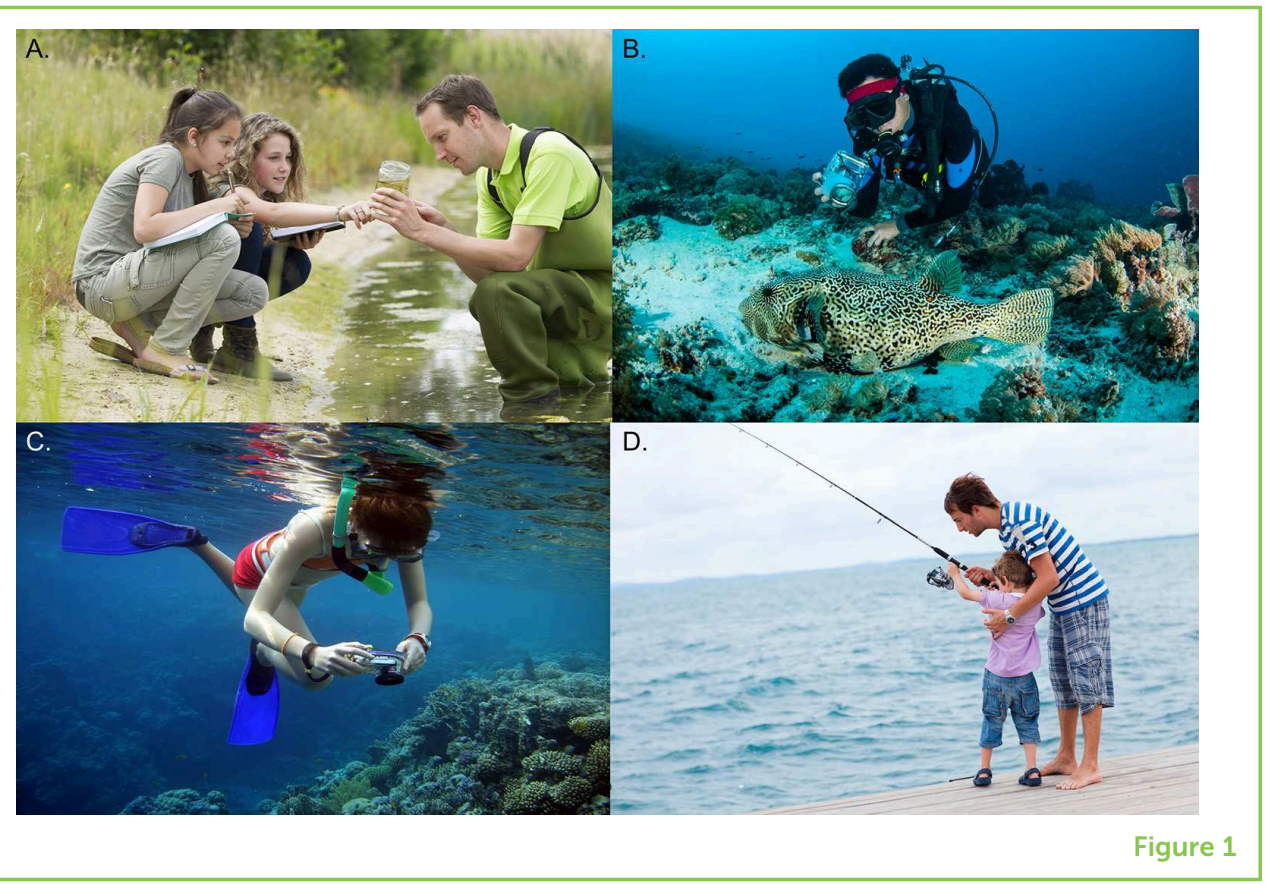

\section{MEDITERRANEAN SEA AND ITS MARINE SPECIES}

The Mediterranean Sea is one of the largest seas in the world, surrounded by 22 different countries from three different continents, Europe, Asia and Africa. The Mediterranean Sea is a unique place, with about 17,000 different marine species. Of these species, about 3,500 live only in the Mediterranean Sea and nowhere else in the world.

Despite its uniqueness and the high number of organisms that live there, the Mediterranean Sea is endangered, because of human activities. Some human activities, like fishing or tourism, overuse of marine resources, pollution of the marine environment can cause the direct destruction of marine ecosystems (communities of interacting species and their environment). Some human activities, such as shipping, have resulted in the introduction of species from other seas. We call these species alien species, and they can create serious problems for the native species living in the Mediterranean Sea [1].

\section{WHAT IS THE PROBLEM WITH ALIEN SPECIES?}

Once in their new environment, some alien species do not manage to survive, because the conditions of the new environment might be too different from those of their previous homes. Other alien species, those that are more adaptable, might really like the new conditions and start reproducing, increasing in numbers and expanding throughout the area they occupy. In some cases, alien species are beneficial to their new homes, taking up useful ecological roles and supporting their native neighbors (for example, becoming a source of food for the 
INVASIVE ALIEN

\section{SPECIES}

Species introduced to an area that survive. reproduce, and expand, causing problems in the new ecosystem.

\section{INTRODUCTION}

PATHWAYS

The modes of introduction of a species to a new location outside its native range. native species or cleaning up polluted water). But, in many cases, alien species have a negative impact on native ecosystems. For example, alien species may compete for food and space with native species, or may be voracious predators of native species. Often, alien species do not have any enemies in their new environment, which gives them an advantage over native species and, in the end, alien species may cause the extinction of some native ones. When an alien species causes big problems in an ecosystem, it is called an invasive alien species.

\section{BUT HOW DO ALIEN SPECIES ARRIVE IN THEIR NEW HOMES?}

A marine species can move into a new area in many different ways, which are called introduction pathways [2]. It is important to identify the introduction pathway that each alien species has used to reach a new area, because this knowledge may help us to stop or control the arrival of new alien species. One way that alien species can reach the Mediterranean Sea is through the Suez Canal, which is a man-made canal connecting the Mediterranean Sea to the Red Sea. The species that reach the Mediterranean through the Suez Canal are called Lessepsian species, from the name of the engineer (Ferdinand de Lesseps) who oversaw the construction of the Suez Canal. Shipping can also assist the introduction of alien species from distant places, as stowaways either within the ballast waters that ships store in special tanks for stability, or attached to the surface of the ship's hull. Humans have also introduced some species to the Mediterranean Sea on purpose, to breed them in aquaculture facilities, and some alien species escaped or were released from public or private aquariums [3].

\section{HOW DO WE KNOW THAT AN ALIEN SPECIES HAS ARRIVED IN THE MEDITERRANEAN SEA?}

In the Mediterranean Sea, new species are frequently arriving through various introduction pathways. Because of the large number of new alien species and the large size of the Mediterranean Sea, it is very difficult to detect new alien species. Scientists from many countries work hard to find, observe, and monitor the alien species here, and collect as much information as possible. However, not only scientists can spot alien species. Many people visit the Mediterranean Sea for swimming, diving, or fishing (Figure 1). These citizens are also invited to report alien species to the blogs and authorities responsible for dealing with this threat. We call this citizen science-the contribution of citizens to the collection of data, which helps scientists. To bring together all the alien species data from various sources so that it is easy to find, the European Commission created the European Alien Species Information Network (EASIN), where people can share information about alien species across Europe, including the Mediterranean Sea. 
Figure 2

Examples of Alien species that have been introduced in the Mediterranean through various pathways.

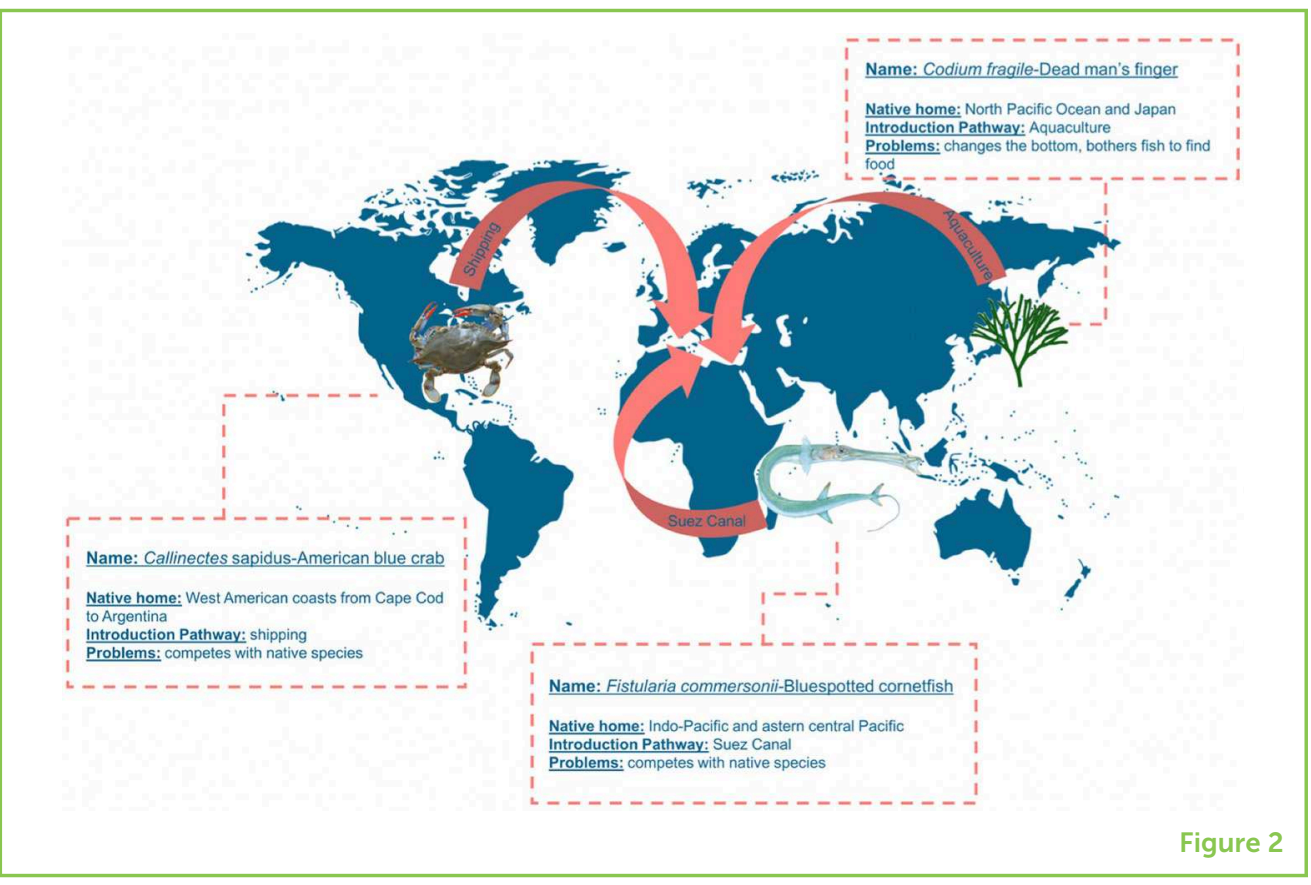

Access is provided via a website (https://easin.jrc.ec.europa.eu/) that is available to everyone who is interested.

\section{WHAT ARE THE MAIN INTRODUCTION PATHWAYS FOR ALIEN SPECIES IN THE MEDITERRANEAN SEA?}

In order to answer this question, we used all the records of alien species from the EASIN database up to January 2014. We found 986 alien species in the Mediterranean Sea. Then, we linked each alien species with at least one introduction pathway. Sometimes this was easy, while for some alien species it was very difficult. To discover introduction pathways, first we need to know the native home of the alien species. Then, depending on where we spotted the alien species the first time, we can deduce the introduction pathway. For example, if we find an alien species, whose native home is the Red Sea, in an area close to the opening of the Suez Canal, we can conclude that this species probably entered the Mediterranean Sea by moving from the Red Sea through the Suez Canal. Similarly, if we see an alien species, whose native home is the Atlantic Ocean, in an eastern Mediterranean port, we can conclude that it probably got there on a ship. However, sometimes it is more complicated, and two or more introduction pathways could be responsible for the introduction of an alien species. In our study, we managed to find one introduction pathway for 799 alien species, and two or more possible pathways for 114 . We could not make reasonable assumptions about the introduction pathways for 73 alien species.

We found that the most important introduction pathway into the Mediterranean Sea is the Suez Canal, which was responsible for the 
Figure 3

The number of alien species found in the Mediterranean Sea. You can see that there is an increase in the number of alien species as we move south-east.

\section{BIODIVERSITY}

The variety of species living in an area.

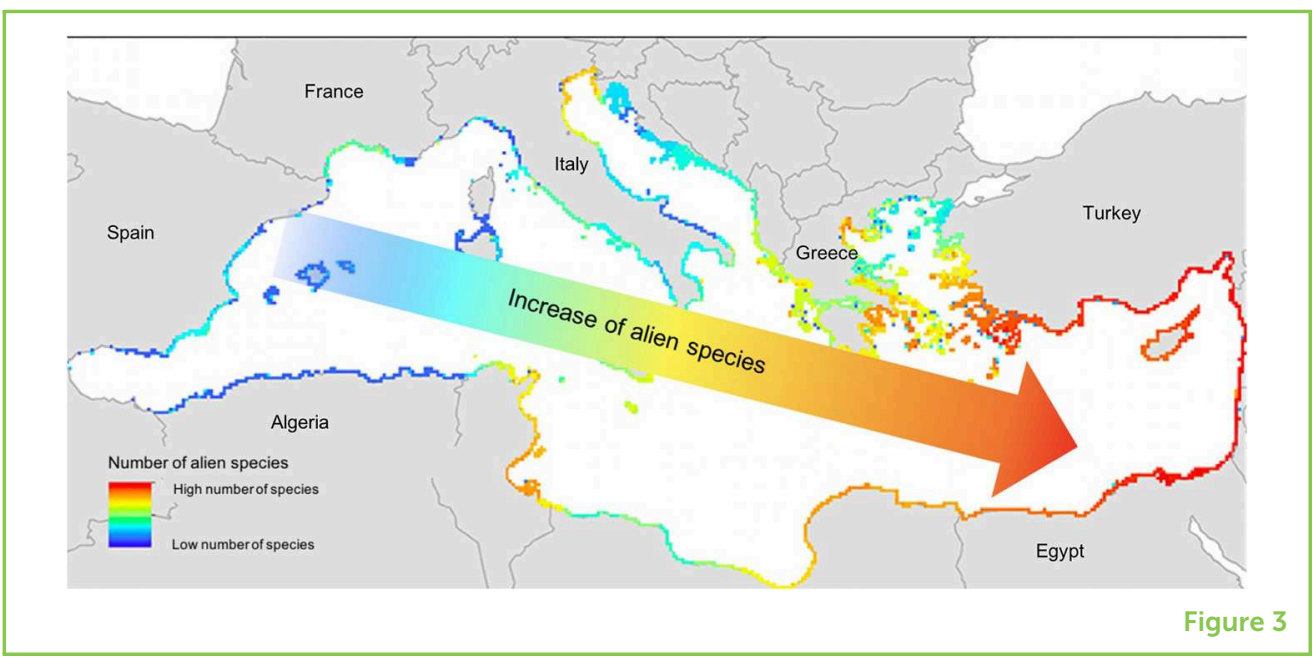

introduction of 420 Lessepsian species. Most of these species are now present in the Eastern part of the Mediterranean Sea [3] (Figure 2). The second most important pathway was shipping, responsible for the introduction of 308 alien species that are scattered all over the Mediterranean, especially close to harbors (Figure 2). Aquaculture was responsible for the introduction of 64 alien species, which are mainly found in two areas with aquaculture facilities, the Thau lagoon (Gulf of Lion, France), and the Venice lagoon (northern Adriatic, Italy) (Figure 2).

\section{DO THESE ALIEN SPECIES AFFECT THE BIODIVERSITY OF THE MEDITERRANEAN SEA?}

We discovered that more alien fish species are present in certain parts of the Mediterranean, like the Levantine Sea and the southeastern Aegean Sea, than in other regions. Alien invertebrate species (animals without spines) exhibited a similar pattern, but also had a high presence along the French coastline, in the Thau lagoon, along the northern Adriatic and the eastern Sicily. Alien algae showed the opposite pattern, with more alien algae species in the western Mediterranean regions. So, our analysis told us that the distribution of alien species differs according to the introduction pathway used and is dependent on the type of alien species (fish, invertebrates, algae). We also found that alien species composition, the pool of all the alien species present in an area, differed among the different regions. Finally, by analyzing the pool of native fish and invertebrates, we found a pattern that was opposite to the pattern of the alien species. In the western Mediterranean, there are more native species than in the eastern Mediterranean, while the eastern Mediterranean has more alien species than the western Mediterranean (Figure 3). So yes, alien species significantly affect the biodiversity of the Mediterranean Sea. 


\section{HOW CAN YOU HELP?}

Scientists and citizens alike need to chip in to help prevent the continued invasion of alien species! But how can regular people help? First, citizens must adopt responsible behaviors that will reduce the introduction of alien species into the Mediterranean Sea. For example, people with home aquariums must never release their marine organisms into the wild. Fishermen, when traveling long distances for fishing, must thoroughly clean their equipment before using it again, because contaminated equipment can transfer organisms from one place to another.

Also, citizens should become informed about the different Citizen Science projects that exist in their countries, through which they can contribute to the early detection and monitoring of marine alien species. In this way, citizens can meaningfully contribute to the prevention of biological invasions, by informing the scientists and the appropriate authorities.

\section{CONCLUDING REMARKS}

Biological invasions are one of the biggest threats for the native ecosystems and species of the Mediterranean Sea. During the last three decades, Mediterranean biodiversity has changed rapidly, more than any other marine region in the world, as a result of human activities, such as shipping, aquaculture, and the opening of the Suez Canal. The Suez Canal and the resulting Lessepsian migration is the most important reason for this rapid introduction of alien species into the Mediterranean. Over the last two decades, the water temperature of the Mediterranean has been warming, especially in the eastern regions, and this trend is expected to continue in the future. These higher temperatures favor the establishment and spread of species that like warm waters, such as Lessepsian immigrants, which normally live in warmer seas. These days, alien species are an important part of many ecosystems, and they may change the way ecosystems function. Knowing the number of alien species in every ecosystem is important, both to understand the trend of change and to also monitor the effects of the alien species and the effectiveness of steps taken to prevent new introductions. It is very important to understand the impact that alien species have on ecosystems, because some alien species can have benefits for native species and their habitats, so those alien species do not need to be controlled. However, other alien species are dangerous for ecosystems. Understanding which species help and which harm an ecosystem helps scientists to prioritize alien species for control or eradication.

\section{ORIGINAL SOURCE ARTICLE}

Katsanevakis, S., Coll, M., Piroddi, C., Steenbeek, J., Ben Rais Lasram, F., Zenetos, A., et al. 2014. Invading the Mediterranean Sea: 
biodiversity patterns shaped by human activities. Front. Mar. Sci. 1:32. doi: 10.3389/fmars.2014.00032

\section{REFERENCES}

1. Babić, I., Hudina, S., and Bielen, A. 2017. Invasion of the Chinese pond mussels - what makes these harmless-looking animals so dangerous? Front. Young Minds 5:56. doi: 10.3389/frym.2017.00056

2. Katsanevakis, S., Zenetos, A., Belchior, C., and Cardoso, A. C. 2013. Invading European seas: assessing pathways of introduction of marine aliens. Ocean Coast. Manage. 76:64-74. doi: 10.1016/j.ocecoaman.2013.02.024

3. Zenetos, A., Gofas, S., Morri, C., Rosso, A., Violanti, D., Raso, J. E. G., et al. Alien species in the Mediterranean Sea by 2012. A contribution to the application of European Union's Marine Strategy Framework Directive (MSFD). Part 2. Introduction trends and pathways. Mediterr. Mar. Sci. 13:328-52. doi: $10.12681 / \mathrm{mms} .327$

SUBMITTED: 11 September 2018; ACCEPTED: 28 June 2019; PUBLISHED ONLINE: 12 July 2019.

EDITED BY: Becky Louize Thomas, School of Biological Sciences, Royal Holloway, University of London, United Kingdom

CITATION: Giovos I, Katsanevakis S, Coll M, Piroddi C, Steenbeek J, Lasram FBR, Zenetos A and Cardoso AC (2019) Human Activities Help Alien Species to Invade the Mediterranean Sea. Front. Young Minds 7:97. doi: 10.3389/frym.2019.00097

CONFLICT OF INTEREST STATEMENT: The authors declare that the research was conducted in the absence of any commercial or financial relationships that could be construed as a potential conflict of interest.

COPYRIGHT () 2019 Giovos, Katsanevakis, Coll, Piroddi, Steenbeek, Lasram, Zenetos and Cardoso. This is an open-access article distributed under the terms of the Creative Commons Attribution License (CC BY). The use, distribution or reproduction in other forums is permitted, provided the original author(s) and the copyright owner(s) are credited and that the original publication in this journal is cited, in accordance with accepted academic practice. No use, distribution or reproduction is permitted which does not comply with these terms.

\section{YOUNG REVIEWERS}

\section{KOREA FOREIGN SCHOOL, AGES: 12-13}

Steve likes memes. Haider likes the color orange and soccer. Atilla loves math and being a humorous, positive person. His hobbies are building a different kind of mechanisms and robots. Hayato loves to read and eat sushi and hamburgers. Lina loves to play competitive tennis. She also likes dogs. Nadya likes pig-sloths, dogs, art, mythology, and magical things. Humayra loves cats, unicorns, pastel fashion, digital painting, and writing in her free time. 


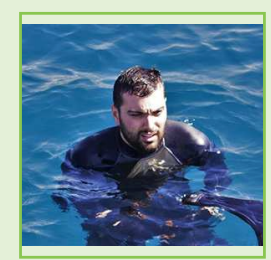

\section{AUTHORS}

\section{IOANNIS GIOVOS}

Ioannis Giovos is the Fisheries Director of iSea, an Environmental Organization based in Thessaloniki Greece. He is interested in the conservation of marine biodiversity in the Mediterranean with an emphasis on marine megafauna and alien species. His research focuses on citizen science, local ecological knowledge, public perceptions, and rapid fishery assessment for collecting biodiversity records and monitoring illegal practices. In the past he also worked for the Tethys Research Institute in Italy. *ioannis.giovos@isea.com.gr
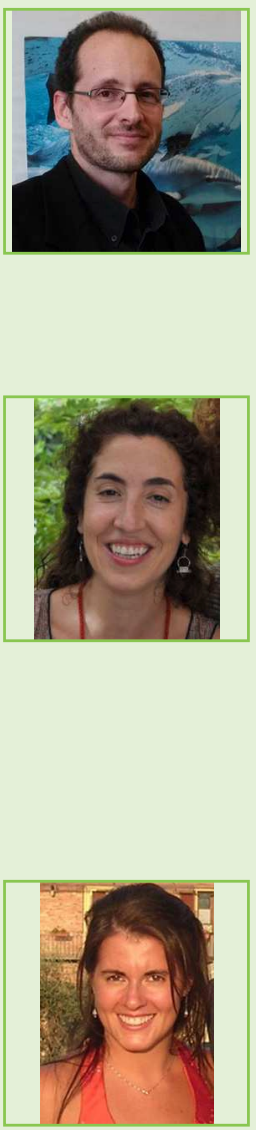

\section{STELIOS KATSANEVAKIS}

Stelios Katsanevakis is a Professor of Marine Ecology in the Department of Marine Sciences at the University of the Aegean (Greece). He is interested in the conservation of marine biodiversity and the impacts of alien species on biodiversity and on humans. Most of his research has been conducted in the Mediterranean Sea. He used to work in the Joint Research Center of the European Commission for the development of the European Alien Species Information Network.

\section{MARTA COLL}

Marta Coll is a Researcher of the Institute of Marine Science (ICM) at the Spanish National Research Council (CSIC) in Barcelona (Spain). Her research focuses on understanding patterns and processes that characterize marine ecosystems and, in particular, changes of, and threats to, marine biodiversity. She studies community and food-web dynamics linked with human activities (such as fisheries, climate change, eutrophication, and invasive species), and how these translate into changes in ecosystem structure and functioning, and services that humans obtain from the ocean.

\section{CHIARA PIRODDI}

Chiara Piroddi is a Scientific Officer in the Unit of Water and Marine Resources at the Joint Research Centre, European Commission. Her main interests are related to the conservation of marine biodiversity, the impacts of cumulative stressors (e.g., fishing, climate change, plastic) in the marine environment and the use of ecosystem modeling tools to support policy decision. The European Seas, particularly the Mediterranean Sea, are her principal case studies.

\section{JEROEN STEENBEEK}

Jeroen Steenbeek is a classically trained software engineer with over 25 years of experience in software development in industrial, commercial, and academic settings. Since 2006 he is one of the core programmers of Ecopath with Ecosim, which is a free and open-source ecosystem modeling software mostly used to better understand how fishing, climate change, and other anthropogenic disturbances affect marine ecosystems. Jeroen really likes his job, and is based at Ecopath International Initiative in Barcelona, Spain. 

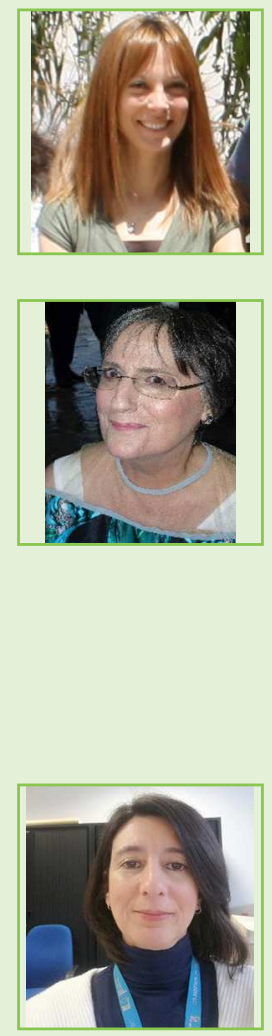

\section{FRIDA BEN RAIS LASRAM}

Frida Ben Rais Lasram is an Associate Professor at the University of Littoral (France). She is interested in the conservation of marine biodiversity and the impacts of global change, such as overfishing, climate change, and biological invasions. The Mediterranean Sea is one of her priority study areas.

\section{ARGYRO ZENETOS}

Argyro Zenetos is a Research Director at the Hellenic Centre for Marine Research. Argyro, who is actively involved with marine alien species since 1997. She has research experience on zoobenthos, environmental impact studies and biodiversity indicators. She is the coordinator of the Hellenic Network on Aquatic Invasive Species (ELNAIS) http://elnais.hcmr.gr/ and Chief Editor of the Mediterranean Marine Science Journal. Argyro is a consultant to the European Environment Agency, UNEP/MAP and JRC; also member of the EASIN Editorial Board, ESENIAS network, ICES/WGBOSV, and Management Committee member in COST1209 and COST17122.

\section{ANA CRISTINA CARDOSO}

Dr. Ana Cristina Cardoso is a Research Officer at the European Commission Joint Research Centre, which she joined in 1995. Since then, she has contributed and coordinated several research and science-policy projects in the fields of biodiversity, freshwater, and marine ecology. Her current research interests include the assessment of alien species and citizen science. She was involved in European Alien Species Information Network (EASIN) conceptual design and she is responsible for its coordination. 